\section{Cognitive functions and fall-related fractures}

SIR: We assessed the cognitive function of elderly patients admitted exclusively because of fall-related fractures. All were living at home at the time of the accident. They underwent a full physical examination on admission, together with a battery of psychometric tests to assess cognitive function: the Mini Mental State Examination (MMSE; Folstein et al, 1975), Benton's (1960) test, and Rey's (1942) complex figure copy and recall. There were 120 patients, with a mean (s.d.) age of 81.4 (8.2) years (110 women, mean age $81.2(8.1)$, median $83 ; 10$ men, mean age 82.8 (8.5); median 84). Most patients $(114 / 120,95 \%)$ had previously had a fall, and 44 $(38 \%)$ had previously had fall-related fractures.

Only $12 \%$ of our population had a normal MMSE score. The mean MMSE result was closer to a dementia score than to a simple mental deterioration (18.92 (6.45); normal value, over 25). Furthermore, performance on Benton's test for non-verbal cognitive functions was poorer than expected on the basis of the MMSE (11.03 (4.91); normal value, over 25), as was the Rey copy test (14.84 (9.94); normal value, over 30$)$ and the Rey recall test (4.55 (4.57); normal value, over 22). These results are in marked contrast with epidemiological data suggesting that only $20 \%$ of 80 -year-olds suffer from dementia. Fall-related fractures and impairment of cognitive functions are thus strongly correlated.

For all elderly people seen for falls, with or without loss of consciousness, the cause of the fall should be examined. Low scoring in psychometric tests is a major risk factor for falls.

BENTON, A. L. (1960) Manuel pour l'application clinique du test de rétention visuelle. Paris: Centre psychologie appliquée.

Folstenn, M. F., Folstern, S. E. \& McHugh, B. R. (1975) “Mini mental status". A practical method for grading the cognitive state of patients for the clinician. Journal of Psychiatric Research, 12, 189-198.

REY, A. L. (1942) L'examen psychologique dans les cas d'encéphalopathie traumatique. Archives des Psychologie, 28, 112.

Department of Neuropsychology

Department of Gerontology

Department of Rehabilitation

A. P. JABOURIAN

C. DE JAEGER

G. FINDJI

G. ARMENIAN

A. HADDAD

Department of Neuropsychology

$\mathrm{CMCH}$

50, rue de Paris

F-95220 Herblay

France

\section{Alcoholism in Kuala Lumpur General Hospital}

SIR: The prevalence of alcoholism in hospitals has generally been reported to be between 10 and $30 \%$ (Moore, 1971; Jariwalla et al, 1979; Jarman \& Kellet, 1979). This study attempted to identify the prevalence of alcoholism and undetected alcoholism in the General Hospital, Kuala Lumpur, and to describe some demographic trends.

Patients from the medical, surgical and orthopaedic wards were screened by the CAGE $(n=621)$ (Bush et al, 1987); a total of 264, which included all positive by the CAGE and an equal number of negatives who were drinkers, were interviewed blindly by the author using DSM-III-R (American Psychiatric Association, 1987). Doctors were asked whether they knew the patients were excessive drinkers or not.

Sixty-six $(11 \%)$ of the patients were alcohol abusers/dependents by DSM-III-R criteria, but only $21(3 \%)$ had been detected by doctors to be drinking excessively. Thirty-five $(53 \%)$ of the 66 were Indians, $13(20 \%)$ were Chinese, $13(20 \%)$ were Malays and $5(7 \%)$ were others (Eurasians and other minority groups).

The overall drinking population comprised 95 Indians, 92 Chinese, 65 Malays and 12 others; of the non-drinkers, $54 \%$ were Malays, $22 \%$ were Indians, $21 \%$ were Chinese, and $3 \%$ were others. The prevalence of alcoholism in this hospital population is $11 \%$. Indians appear to be more vulnerable to the effects of alcohol; it also appears that doctors have a stereotype of the excessive drinker as being poor, male, Indian and ill. Excessive drinkers not fitting this description were missed.

No female alcoholic was identified in this study, although $14 \%$ of the drinkers were women; the stigma and taboos associated with Asian women who drink may explain this.

The prevalence of alcoholism in the general population in Malaysia is unknown.

The majority in this study came from social class 3 and below, which corresponds to the general occupational distribution of the population in the hospital and in the catchment area serving it.

The Indians in this study were mainly immigrants from South India, and one wonders if such racial trends are noticed in other Asian immigrant populations.

American Psychiatruc Associntion (1987) Diagnostic and Statistical Manual of Mental Disorders (3rd edn, revised) (DSM-III-R). Washington, DC: APA.

Bush, B., Shaw, S., Clearly, P., et al (1987) Screening for alcohol abuse using the CAGE questionnaire. American Journal of Medicine, 82, 231-235. 